Cahiers $d u$ MONDE RUSSE

\section{Cahiers du monde russe}

Russie - Empire russe - Union soviétique et États indépendants

$57 / 4 \mid 2016$

Varia

\title{
Tim Buchen, Malte Rolf, éd., Eliten im Vielvölkerreich, Imperiale Biographien in Russland und Österreich-Ungarn (1850-1918)
}

\section{Gábor T. Rittersporn}

\section{(2) OpenEdition}

1 Journals

Édition électronique

URL : http://journals.openedition.org/monderusse/10012

DOI : $10.4000 /$ monderusse. 10012

ISSN : $1777-5388$

Éditeur

Éditions de l'EHESS

\section{Édition imprimée}

Date de publication : 1 octobre 2016

Pagination : $918-920$

ISBN : 978-2-7132-2542-0

ISSN : $1252-6576$

\section{Référence électronique}

Gábor T. Rittersporn, «Tim Buchen, Malte Rolf, éd., Eliten im Vielvölkerreich, Imperiale Biographien in Russland und Österreich-Ungarn (1850-1918) », Cahiers du monde russe [En ligne], 57/4 | 2016, mis en ligne le 01 octobre 2016, Consulté le 23 septembre 2020. URL : http://journals.openedition.org/ monderusse/10012 ; DOI : https://doi.org/10.4000/monderusse.10012 
by a shared activity. ${ }^{2}$ His definition also fits literary and journalistic depictions of obshchestvo as le grand monde or good society. The court society of Catherinian Russia, as represented by French theater, therefore suggests a potentially more accurate, or at least a fresher, reading of Russian social development than that established by the "new" social and cultural histories of the 1960s-2000s. Islands of community, including emotional and theater communities (remember also the intellectual circles of the early nineteenth century), amid a sea of moving associations: this image may offer an alternative perspective on social relationships in Russia. Communities, particularly peasant communes and labor unions, always have been present in social history. But is it time for these micro-communities, conceived within a larger framework, to take center stage? There is something here to discuss, and Evstratov should be congratulated for contributing a solid piece of work to an ever-changing conversation.

1 - James Cracraft has written several books on the Petrine cultural revolution in architecture, imagery, and language. For an overview, see James Cracraft, The Revolution of Peter the Great (Cambridge, MA, 2003).

2 - Slovar' Akademii rossiiskoi [Dictionary of the Russian Academy], 6 vols. (SPb., 1789-1794).

\section{Elise Kimerling Wirtschafter}

California State Polytechnic University at Pomona

Tim BUCHEN, Malte ROLF, éd.

\section{Eliten im Vielvölkerreich}

\section{Imperiale Biographien in Russland und Österreich-Ungarn (1850-1918)}

Berlin : De Gruyter Oldenbourg, 2015, 411 p.

L'histoire sociale et les soi-disant tournants culturel et visuel ont éloigné les ouailles de Clio du genre biographique. Même les collègues qui tentent d'explorer l'individu comme sujet historique s'abstiennent de chroniquer la vie de leurs protagonistes. La confrérie a longtemps eu tendance à mépriser l'approche biographique. Celle-ci lui semblait relever du roman historique et psychologique ou, au meilleur des cas, du journalisme plus ou moins bien informé. L'histoire qu'on écrivait avec une « $\mathrm{h} »$ majuscule, et qui consistait en des problématiques spécifiques et révélatrices de leur temps, ne se confondait pas avec celle de la personne. La tendance commence à changer, mais les réticences restent fortes.

Il faut donc une bonne dose de témérité pour annoncer dans le sous-titre d'un ouvrage qu'il traite de biographies. Circonstance atténuante peut-être, ces biographies sont qualifiées d' « impériales ». Car, on assiste aussi à un tournant impérial, à l'étude d'empires, une notion qu'on ne définit pas tout à fait clairement. Si l'on se fonde, comme c'est souvent le cas, sur des critères comme la multi-ethnicité, 
l'administration centralisée, une organisation régionale et une fiscalité décidées au sommet de l'État ainsi que l'expansionnisme, alors peu de choses empêchent de taxer d'empire, disons, le Royaume de Hongrie du XIV ${ }^{\mathrm{e}}$ siècle, quand le pays s'étendait, en partie grâce à des conquêtes, entre les mers Baltique et Adriatique sous une cour centralisatrice, ou la Pologne de l'entre-deux-guerres, sous la houlette de Varsovie, avec ses minorités, qui formaient un cinquième de sa population, et avec ses visées sur des territoires ukrainiens, lituaniens et tchécoslovaques.

Les éditeurs et les auteurs de l'excellent volume ont de la chance, car leurs recherches portent sur la Russie et l'Autriche-Hongrie, que leurs maîtres qualifiaient d'empires, même si la dénomination ne faisait pas toujours l'unanimité parmi leurs sujets. Les dix-neuf participants au projet n'avaient donc aucun besoin de risquer de définitions hasardeuses. Ce ne sont pas les empires en tant que tels qui les intéressent, mais l'expérience et le destin de gens qui contribuèrent à la construction et à la gestion des deux empires et, occasionnellement, à leur dissolution aussi, sans qu'ils en soient nécessairement conscients. Il serait certainement de bon ton de regretter qu'ils n'écrivent qu'à propos d'hommes, mais on ne trouve pas plus de femmes parmi leurs acteurs potentiels que parmi les dignitaires de l'Église catholique. Leurs héros sont des administrateurs, des militaires et des intellectuels peu connus, à l'exception de Vasilij Šul'gin, de Gustaf Mannerheim et de Tomaš Masaryk.

Au premier coup d'œil, le choix des deux empires peut surprendre. Les différences sont nombreuses. L'empire autrichien n'était pas une autocratie. Il a pris la forme d'une double monarchie entre le milieu du dix-neuvième siècle et la Grande Guerre, la période qui intéresse les auteurs. Même si l'on peut comparer certaines prérogatives du grand-duché de Finlande à celles dont bénéficiait la Hongrie, on chercherait en vain, par exemple, une armée finlandaise ou des Finnois dans le gouvernement de la Russie, alors que les Magyars avaient leurs guerriers sous leur propre drapeau et des ministres dans le cabinet de Vienne. L'étendue territoriale de l'empire russe et les problèmes qu'elle posait n'avaient pas leurs équivalents dans la monarchie danubienne.

Malgré tout, l'attachement à l'institution impériale et à la formule d'un État centralisé, qui primait leurs éventuelles loyautés ethniques et religieuses, était caractéristique de nombreux administrateurs, militaires, politiciens et intellectuels aussi bien en Russie qu'en Autriche-Hongrie. Il en allait de même de leur carrière, qui les emmenait dans diverses contrées du pays, de leur apprentissage comme sujets dévoués et citoyens responsables dans divers contextes locaux et de leur rôle d'intermédiaires entre le centre et la périphérie.

S'ils étaient souvent étrangers à l'environnement social et culturel de leur lieu de service, ce désavantage avait des chances de tourner à l'avantage du régime, car il facilitait la motivation de ses serviteurs à uniformiser la gestion des empires. Néanmoins, dans les deux cas, l'homogénéisation était susceptible de provoquer des tensions, surtout si elle allait de pair, comme dans l'empire des tsars, avec des tentatives énergiques de russification. L'unification que les élites cherchaient était étroitement liée à leur expérience cosmopolite, qui suggérait que l'appartenance 
nationale et le dévouement à un État multinational fussent la norme pour tous les sujets de leurs empereurs respectifs.

Les déplacements des administrateurs d'une région à l'autre créaient des réseaux sociaux et des rapports entre divers territoires. Si les liens entre notables pouvaient se tisser grâce à des origines ethniques communes, ils ne remettaient pas en cause le principe impérial. L'expertise que les élites pouvaient accumuler dans les provinces était un atout précieux pour les plus ambitieux qui voulaient monter aux administrations centrales ou devenir des conseillers écoutés à la capitale.

Les modèles de comportement des élites étaient assez différents dans les deux empires. Ainsi, il était inimaginable dans l'administration des Habsbourg que le gouverneur d'une province lointaine se déclarât non simplement le représentant du souverain mais, en tout sérieux, « demi-tsar ». On ne lui aurait pas pardonné cette incartade sur les bords du Danube, alors que sur les bords de la Neva, on comprenait qu'un fidèle serviteur de sa majesté, tel Konstantin von Kaufman, n'eût pas trouvé meilleure solution pour impressionner les indigènes du Turkestan et on fermait les yeux d'autant plus volontiers qu'il s'agissait d'un officiel fidèle ayant déjà fait preuve de ses talents dans diverses régions périphériques de l'empire.

Les deux élites étaient confrontées, entre autres, à un problème commun qui déstabilisait les deux empires, tant de l'intérieur que de l'extérieur, et qui mérite d'être mis en évidence, celui de leur adaptation à un monde moderne. Le caractère du problème et les tentatives pour le surmonter n'étaient pas les mêmes à Vienne qu'à Saint-Pétersbourg. Mais il n'était rien de plus naturel, dans les deux monarchies, qu'à côté de conservateurs acharnés, les milieux politiques, les administrations, les professions libérales et, à un moindre degré, l'armée comptent des réformateurs tantôt prudents, tantôt courageux dans leurs rangs. Indépendamment de leurs idées et de leurs projets, ils envisageaient les changements dans le cadre des empires, qu'ils voulaient sauver à tout prix.

Aussi sceptique soit-on concernant les mérites du genre biographique, force est de constater que ce volume est une réussite. Les éditeurs et les auteurs ont dégagé des moments communs dans les itinéraires professionnels et l'évolution des convictions d'individus qui appartenaient à des régimes bien différents. Ils sont parvenus à saisir les éléments de la carrière de leurs héros (et antihéros), éléments indissociables d'un parcours dans le contexte de monarchies multi-ethniques, composées de territoires et de peuples qu'il fallait intégrer à une patrie restée, pour le bonheur des uns ou le malheur des autres, hypothétique.

Gábor T. Rittersporn CNRS 